\title{
Perancangan Sistem Informasi Inventory Data Barang Pada PT. Andalas Berlian Motors
}

(Studi Kasus : PT Andalas Berlian Motors Bukit Tinggi)

Okta Veza $^{1}$, M.Ropianto ${ }^{2}$

Program Studi Teknik Informatika, STT Ibnu Sina, Batam

e-mail: Okta@STT-Ibnusina.ac.id

\begin{abstract}
Abstrak
Komputer telah menjadi alat bantu utama dalam tiap kegiatan manusia. Tidak hanya untuk aplikasi bisnis, namun juga dalam kegiatan sehari-hari dari setiap perusahaan. Hal ini menunjukkan bagaimana komputer telah menjadi bagian dari evolusi manusia terhadap teknologi. Penelitian yang dilakukan pada PT. Andalas Berlian Motors Bukittinggi, berorientasi pada pengolahan data Inventory dan penyajian informasi secara komputerisasi. Dalam artian sistem yang akan dirancangan mampu menyelesaikan permasalahan yang dihadapi mulai dari pengolahan data inventory yang masih dilakukan secara manual serta proses penyajian informasi yang tidak efisien dan akurat serta kurangnya efisiensi waktu. Untuk itu diperlukan pengoptimalan penggunaan komputer terhadap pemrosesan data dengan perancangan sebuah sistem informasi yang diaplikasikan kedalam bahasa pemrograman Java dan database MySQL agar dapat memecahkan permasalahan-permasalahan yang ada dengan mampu menjawab kebutuhan perusahaan.
\end{abstract}

Kata Kunci : Sistem Informasi, Inventory, Java, MySQL.

\begin{abstract}
Computers have become a major tool in every human activity. Not only for business applications, but also in the day-to-day activities of every company. This shows how computers have become part of human evolution of technology. Research conducted at PT. Andalas Berlian Motors Bukittinggi, oriented on Inventory data processing and computerized information presentation. In the sense that the system will be designed to solve the problems encountered ranging from inventory data processing is still done manually and the process of inefficient and inaccurate information presentation and lack of time efficiency. For that we need to optimize the use of computers to the data processing with the design of an information system that is applied into the Java programming language and MySQL database in order to solve the existing problems by being able to answer the needs of the company.
\end{abstract}

Keywords : Information Systems, Inventory, Java, MySQL.

\section{PENDAHULUAN}

$\mathrm{D}$ ewasa ini perkembangan ilmu pengetahuan, teknologi dan cara kerja manusia mengalami perkembangan yang sangat pesat sekali. Pekerjaan yang dulunya dilakukan dengan cara tradisional dan memerlukan banyak waktu dalam 
menyelesaikannya sekarang dapat dilakukan dengan bantuan peralatan yang canggih dan tidak memerlukan waktu yang terlalu lama dalam menyelesaikannya.

PT Andalas Berlian Motors adalah PT. KRAMA YUDHA BERLIAN MOTORS yaitu pusat dari semua cabang Berlian Motors dan mempunyai wewenang sebagai agen tunggal pemegang merek (ATPM) Mitsubishi yang bertempat di Jakarta.

Dahulunya PT. Andalas Berlian Motors bernama PT. Alfa Kencana akan tetapi sekitar tahun 1985 mengalami kemunduran atau bangkrut, maka dibeli oleh PT. Sumatera Berlian Motors yang bertempat di Medan, yang akhirnya diganti dengan PT. Andalas Berlian Motors yang bertempat di Padang dan Bukittinggi.

Demikian pula halnya dengan PT. Andalas Berlian Motors Bukittinggi. Dalam meningkatkan usahanya selalu memberikan kemudahan kepada para konsumen. Untuk pengontrolan persediaan barang, barang yang dimaksud disini adalah data mobil dengan nama produk Mitsubishi motors. Namun dalam hal pengolahan data persediaan mobil sebelumnya perusahaan tersebut mempergunakan sistem manual dengan memakai buku sebagai media pencatatan data yang masuk, sehingga dapat dibayangkan susahnya mendapatkan informasi keadaan dan jumlah mobil yang telah dipasarkan ke konsumen dan pengaruhnya terhadap stock. Dilihat dari banyaknya masalah yang timbul akan memberikan sedikit sekali keuntungan bagi perusahaan. Berdasarkan uraian di atas diperlukan suatu program aplikasi yang dapat membantu dalam pengolahan data mengenai persediaan mobil, maka direncanakan sebuah program aplikasi yang dapat membantu dalam mengatasi permasalahan tersebut yakni sebuah Sistem Informasi yang mamapu mengotrol persedian barang di PT Andalas Berlian Motors Bukittinggi.

\section{FRAMEWORK SISTEM}

Penulis akan memberikan gambaran langkah-langkah yang mencakup dari awal penelitian sampai dengan akhir penelitian dalam bab ini. Masing-masing tahapan dalam Kerangka kerja penelitian ini dapat dilihat pada gambar 3.1 dibawah ini.

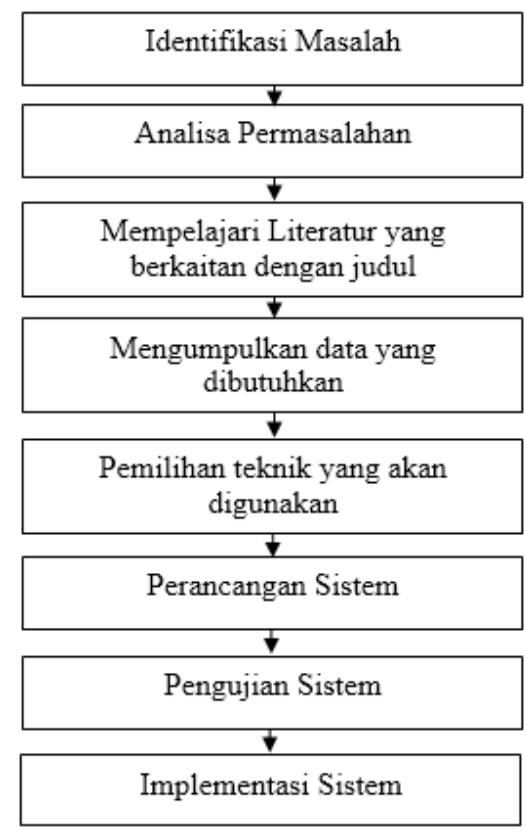

Kerangka Kerja Penelitian 


\section{Identifikasi Masalah}

Pada tahap ini dirumuskan masalah yang akan menjadi objek penelitian. Perumusan masalah dilakukan untuk menentukan masalah apa saja yang terdapat pada objek penelitian serta memberikan batasan dari permasalahan yang akan diteliti.

Inventory adalah aktiva penting yang dimiliki oleh perusahaan PT.Andalas Berlian Motors Bukittinggi maka harus dilakukan pengendalian interen yang baik untuk menjaga persediaan tersebut agar sesuai dengan permintaan pasar. Dalam hal ini dibutuhkan sistem yang bisa membaca kebutuhan persediaan mobil digudang sehingga perusahaan mampu menjawab kebutuhan konsumen dan perusahaan juga mampu mencegar terjadinya penumpukan mobil digudang.

\section{Analisa Permasalahan}

Langkah analisis masalah adalah langkah untuk dapat memahami masalah yang telah ditentukan ruang lingkup atau batasannya. Dengan menganalisa masalah yang telah ditentukan tersebut, maka diharapkan masalah dapat dipahami dengan baik. Teknik analisis yang digunakan dapat dilakukan dengan beberapa tahap berikut:

1. Tahap identify yaitu: mengidentifikasi permasalahan yang terjadi

2. Tahap understand yaitu: memahami lebih lanjut tentang permasalahan yang ada dengan cara melakukan pengumpulan data yang dibutuhkan

3. Tahap analyze yaitu: mencari kelemahan-kelemahan sistem yang ada dan mengumpulkan informasi tentang kebutuhan-kebutuhan lebih lanjut yang diperlukan oleh pemakai.

Masalah yang dihadapi saat penelitian ini dilakukan adalah ketika terjadi permintaan pasar yang tinggi sementara persediaan tidak tersedia di gudang dan ketika rendahnya permintaan pasar perusahan mampu mencegah terjadinya penumpukan barang digudang.

\section{Mempelajari Literatur Yang Berkaitan Dengan Judul}

Berdasarkan pemahaman dari masalah, maka ditentukan tujuan yang akan dicapai dari penulisan ini. Pada tujuan ini ditentukan target yang dicapai, terutama yang dapat mengatasi masalah-masalah yang ada. Setelah masalah dianalisa, maka dipelajari literatur yang berhubungan dengan permasalahan. Kemudian literatur- literatur yang dipelajari tersebut diseleksi untuk dapat ditentukan literatur mana yang akan digunakan dalam penelitian ini. Sumber literatur didapatkan dari perpustakaan, jurnal, artikel, yang membahas tentang inventory persediaan barang, dan bahan bacaan lain yang mendukung penelitian ini.

\section{Mengumpulkan Data-data Yang Dibutuhkan}

Dalam tahap pengumpulan data dilakukan beberapa cara yaitu :

1. Melakukan studi pustaka dengan membaca buku- buku yang menunjang untuk dapat menganalisa data dan informasi yang didapat.

2. Studi lapangan

Yaitu pengamatan secara langsung ditempat penelitian sehingga permasalahan yang ada dapat diketahui secara jelas.

3. Wawancara

Wawancara dilakukan dengan pihak yang terkait yang bertujuan untuk mendapatkan data atau informasi yang dibutuhkan. Pada penelitian ini pihak yang di wawancarai adalah Manajer PT. Andalas Berlian Motors, HRD, Pemasaran dan Kepala Gudang. 


\section{Pemilihan Teknik Yang Akan Digunakan}

Tahap ini bertujuan untuk menentukan teknik yang digunakan dalam pengendalian persediaan mobil dengan menggunakan pemodelan ( DFD) Dataflow Diagram dan Analisa Sistem informasi yang meliputi analisa sistem informasi yang sedang berjalan dan Analisa sistem informasi yang diusulkan.

\section{Perancangan Sistem}

Setelah menentukan model yang akan digunakan maka tahap selanjutnya adalah merancang sistem. Pada perancangan sistem akan dilakukan beberapa tahap kegiatan sebagai berikut:

1. Perancangan Gelobal disebut juga dengan desain teknis sistem secara fisik (Physical System Design) atau disebut juga dengan desain internal (internal design). Perancangan terinci merupakan bentuk fisik atau bagan arsitektur sistem yang akan dibangun.

2. Rancangan Output merupakan produk dari sistem infromasi atau merupakan hasil dari proses yang tersimpan pada suatu media penyimpanan yaitu database. Output dari suatu hasil proses tersebut akan ditampilkan pada media printer.

3. Rancangan file merupakan perancangan tabel dalam database yang telah ditentukan yang digunakan untuk menyimpan data yang di inputkan

4. Rancangan input merupakan perancangan alat pemasukan data yang dibutuhkan dalam proses pembuatan laporan yang diinginkan dalam pengambilan keputusan.

\section{Pengujian Sistem}

. Tujuan utama dari pengujian sistem adalah untuk memastikan bahwa elemenelemen atau komponen-komponen dari sistem telah berfungsi sesuai dengan yang diharapkan. Pengujian perlu dilakukan untuk mencari kesalahan-kesalahan atau kelemahan-kelemahan yang mungkin terjadi.

\section{Implementasi Sistem}

Tahap implementasi adalah tahap akhir dalam menggambarkan sistem, yaitu meletakan sistem agar siap untuk dioperasikan. Implementasi berguna untuk mempermudah penerapan sistem yang disiapkan agar pengentrian data sampai pada penyajian informasi sesuai dengan prosedur yang telah direncanakan.

Sebelum program diterapkan, program harus bebas terlebih dahulu dari kesalahankesalahan yang akan terjadi. Program diuji ditiap modul dan dilanjutkan dengan pengujian ke semua modul yang telah dirangkai. Kesalahan yang mungkin terjadi dapat di klasifikasikan dalam tiga bentuk, yaitu:

1. Kesalahan bahasa (Language errors) atau disebut juga kesalahan penulisan (Syntaax errors), adalah kesalahan dalam penulisan kode program yang tidak sesuai dengan yang sudah di isyaratkan.

2. Kesalahan waktu proses (Runtime errors) adalah kesalahan yang terjadi sewaktu program dijalankan. Kesalahan ini akan menyebabkan proses program terhenti sebelum selesai pada saatnya karena compiler menemukan kondisi yang belum terpenuhi yang tidak terbiasa dikerjakan.

3. Kesalahan logika (Logical errors) adalah kesalahan dari logika program yang dibuat. 


\section{ANALISA SISTEM}

\section{Aliran Sistem Yang Sedang Berjalan}

Tahap analisis dilakukan setelah tahap perencanaan sistem, tahap ini merupakan tahap yang keritis karena kesalahan dalam tahap ini menyebabkan kesalahan pada tahap selanjutnya. Analisis yang dimaksudkan untuk melakukan analisa dan merinci satu persatu keadaan bagian-bagian yang terkait dalam pengolahan data inventory mobil di PT Andalas Berlian Motors Bukittinggi. Hal ini dilakukan agar dapat memberikan gambaran secara menyeluruh akan rancangan sistem yang dibahas sebelumnya dan mengetahui apakah sistem yang dibuat sudah sesuai dengan kebutuhan perusahaan. Apabila terdapat kekurangan dalam sistem ini maka perlu dilakukan evaluasi untuk lebih dikembangkan.

Analisa Sistem Inventory Data Mobil Saat Ini Pada PT.Andalas Berlian Motors Bukittinggi.

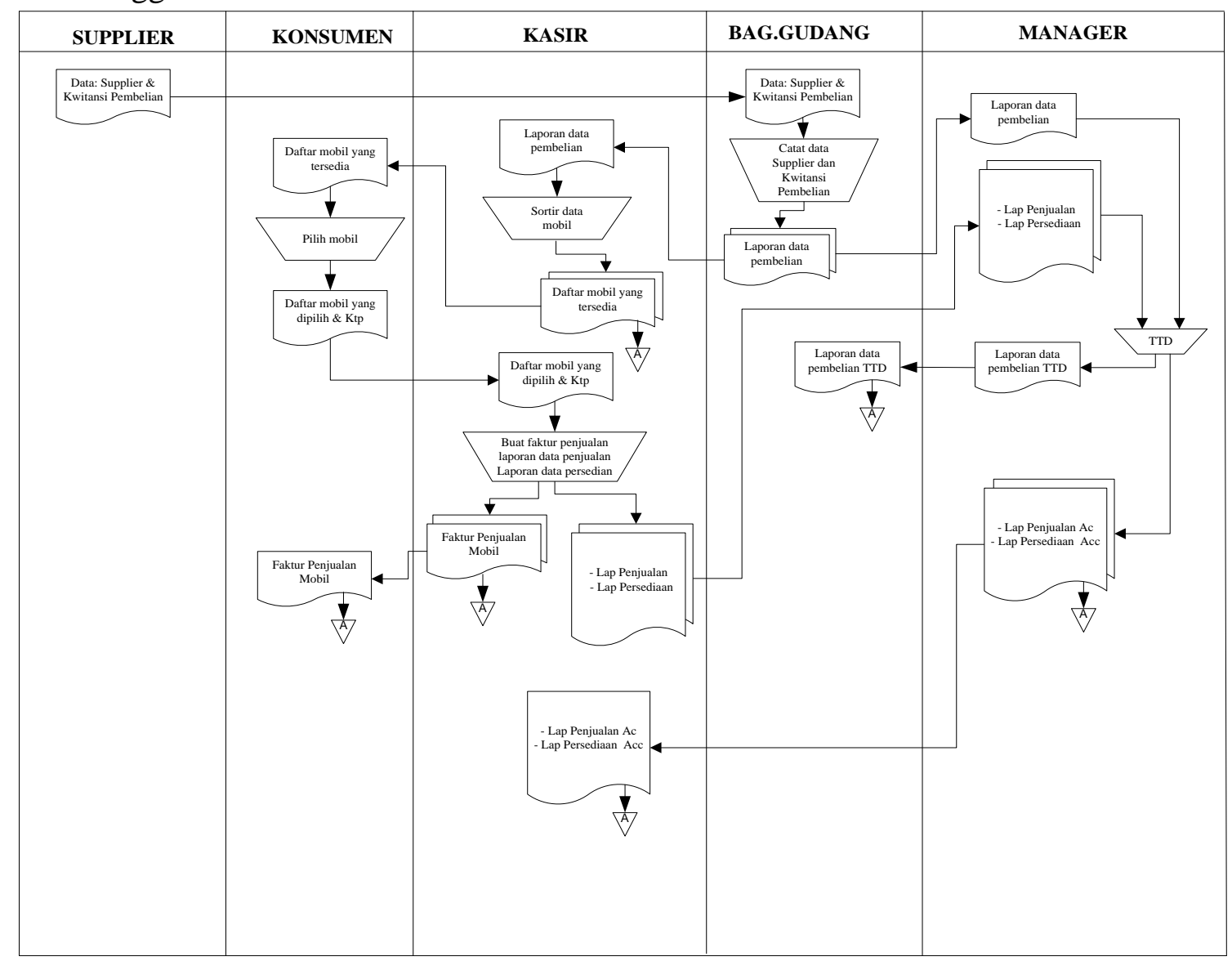

Gambar 3.1 Aliran Sistem Informasi Inventory PT.Andalas Berlian Motors Bukittinggi Saat Ini

\section{Analisis Sistem Yang Diusulkan}

Dalam aliran sistem informasi yang diusulkan ini perubahan mendasar terjadi pada bagian gudang. Adapun bentuk aliran sistem informasi inventory data mobil pada PT.Andalas Berlian Motors Bukittinggi dapat dilihat pada gambar 3.2 dibawah ini : 


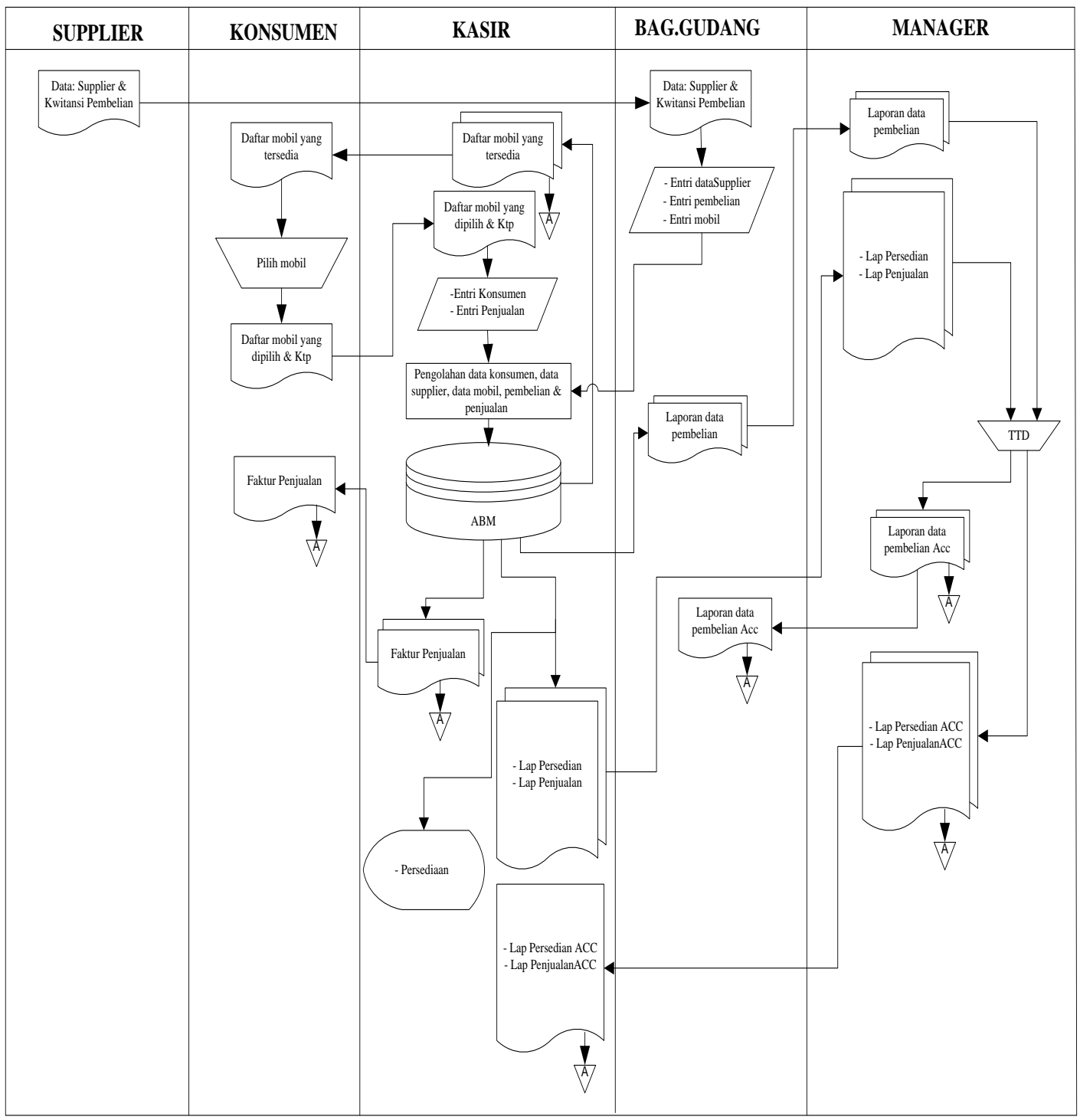

Gambar 3.2 Aliran Sistem Informasi Inventory PT.Andalas Berlian Motors Bukittinggi yang diusulkan

\section{HASIL DAN PEMBAHASAN}

Dalam perancangan global, diuraikan bagan arsitektur sistem yang diusulkan berupa HIPO (Hierarchy Plus Input Process Output), DFD (Data Flow Diagram), dan ERD (Entity Relational Diagram).

\section{HIPO (Hierarchy Plus Input Process Output)}

HIPO yang dirancang untuk Sistem Informasi Inventory Data Mobil di PT.Andalas Berlian Motors dapat dilihat pada Gambar 4.1 dibawah ini : 


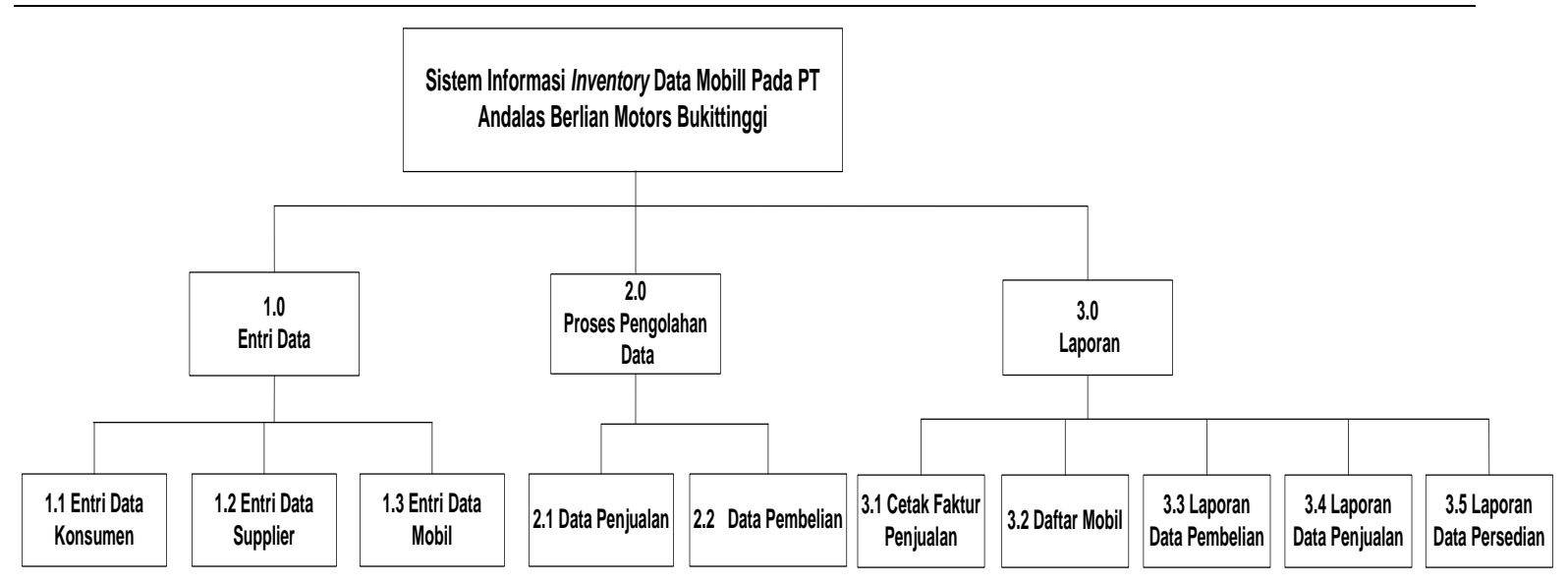

\section{Gambar 4.1 HIPO Sistem Informasi Inventory Data Mobil Pada PT.Andalas Berlian Motors Bukittinggi}

\section{DFD (Data Flow Diagram)}

Data Flow Diagram Sistem Informasi Inventory Data Mobil pada PT.Andalas Berlian Motors Bukittinggi dapat diuraikan sebagai berikut:

a. CD (Context Diagram)

Diagram ini adalah diagram level tertinggi (zero level) dari DFD yang menggambarkan hubungan sistem dengan lingkungan luarnya. Adapun bentuk konseptual dari Context Diagram dapat dilihat pada Gambar 4.2 berikut:

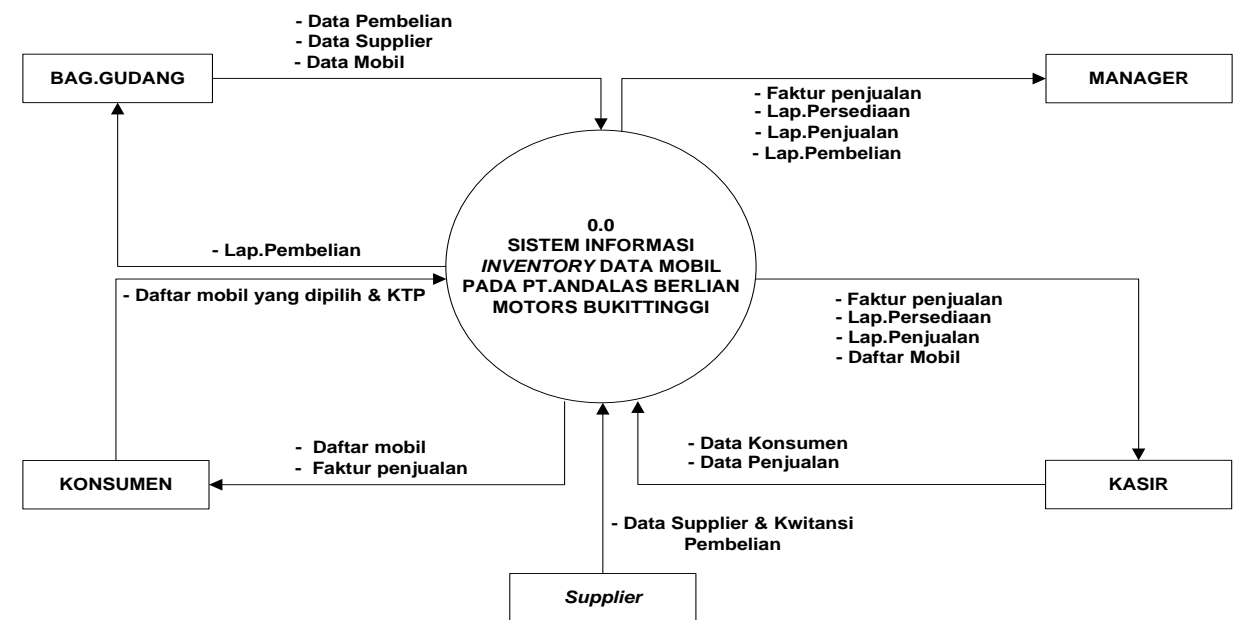

Gambar 4.2 Context Diagram Sistem Informasi Inventory Data Mobil Pada

DFD (Data Flow Diagram) Level 0 PT.Andalas Berlian Motors Bukittinggi

Untuk lebih jelas mengenai gambaran Data flow diagram Sistem Informasi Inventory data mobil pada PT.Andalas Berlian Motors Bukittinggi dapat dilihat pada gambar 4.3 berikut ini : 


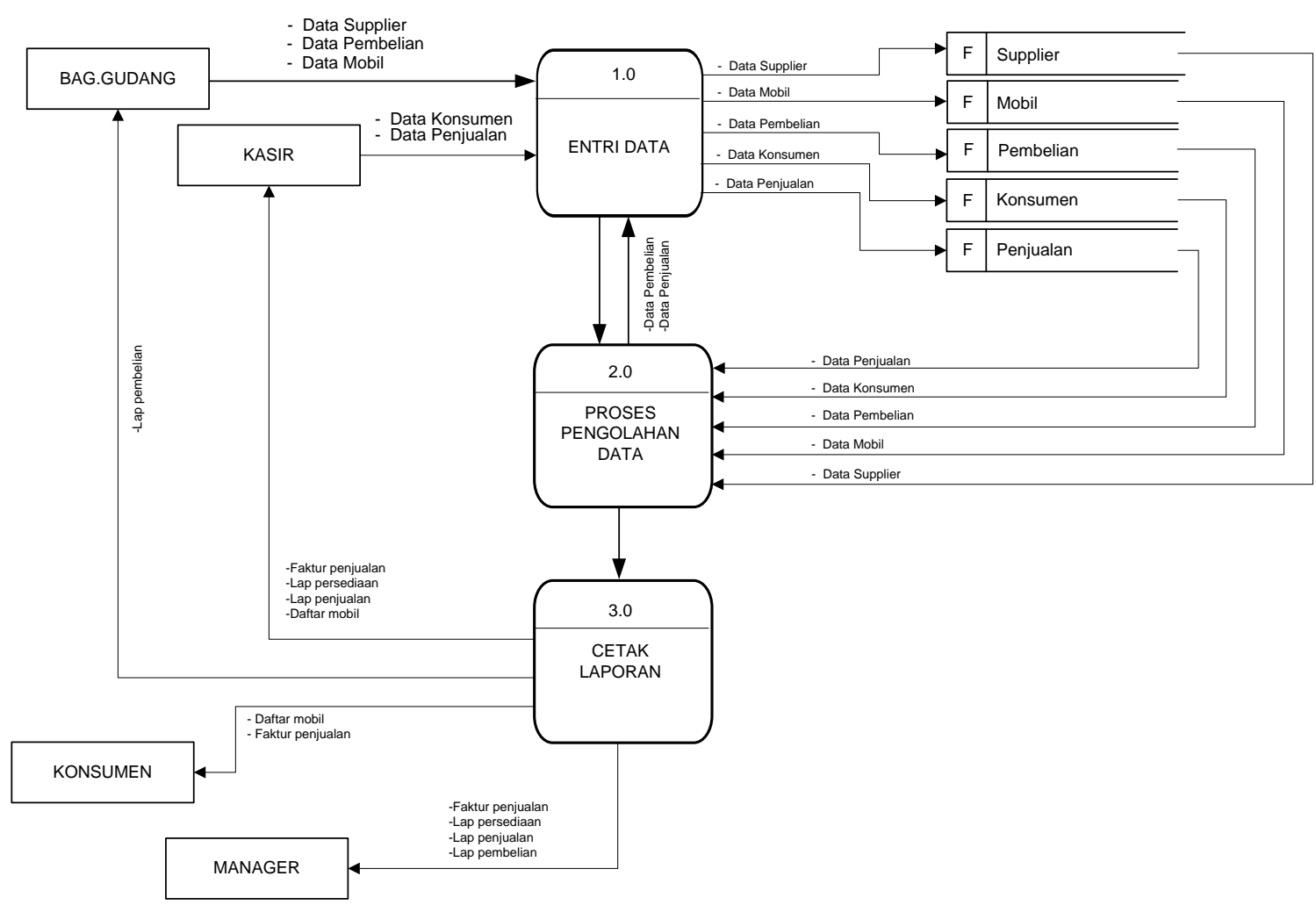

\section{Gambar 4.3 DFD Level 0 Sistem Informasi Inventory Data Mobil Pada PT.Andalas Berlian Motors Bukittingg}

\section{ERD (Entity Relationship Diagram)}

Entity Relationship Diagram (ERD) merupakan gambaran tentang relasi dari setiap entity atribut dari file yang digunakan untuk menggabungkan atau menghubungkan data sehingga dapat dirancang laporan atau input data yang di inginkan.

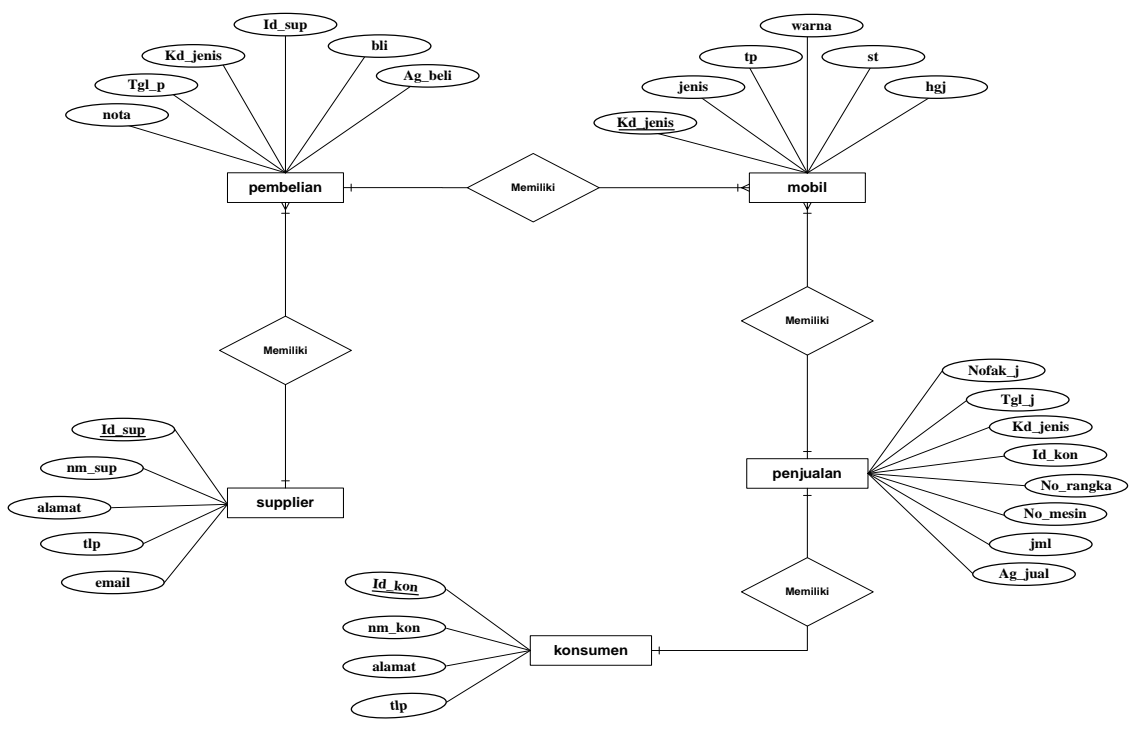
Gambar 4.4 ERD Sistem Informasi Inventory Data Mobil Pada PT.Andalas
Berlian Motors Bukittinggi 
Veza, Ropianto

\section{Output}

Berikut Output yang dihasilkan dari Analisa yang telah dilakukan

1. Laporan data pembelian Perhari

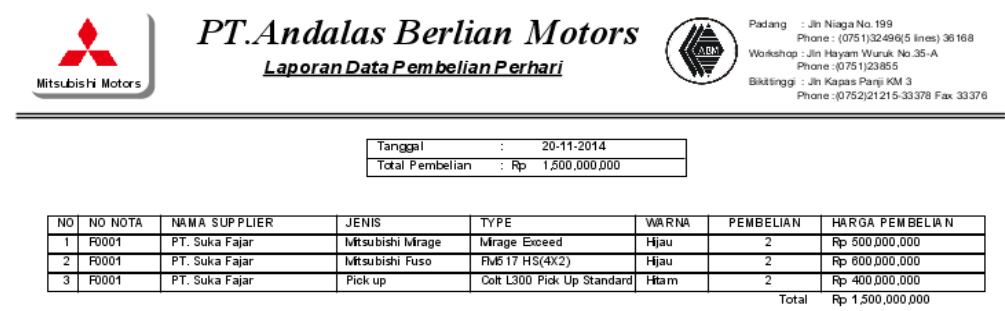

Sumbar, 20 Novernber 2014

PT Anchlas Berlian Motors

Manager

2. Laporan data pembelian perbulan

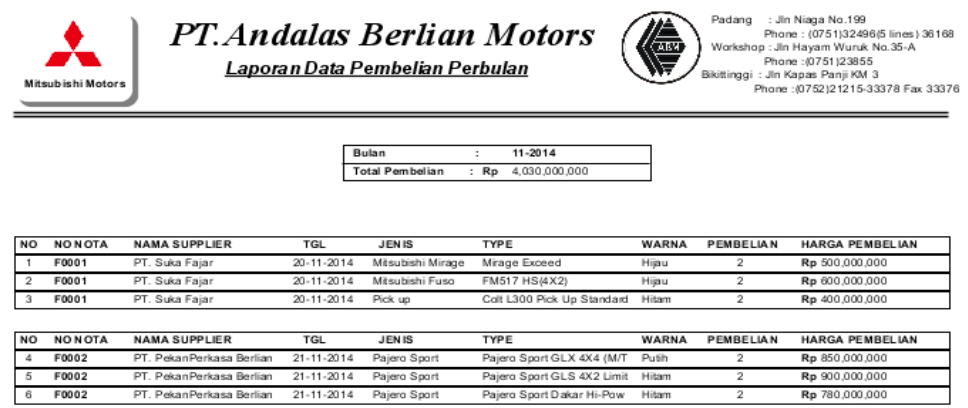

Sumbar, 20 November 2014
PT Andalas Berfian Motors

Manager

3. Laporan data pembelian Pertahun

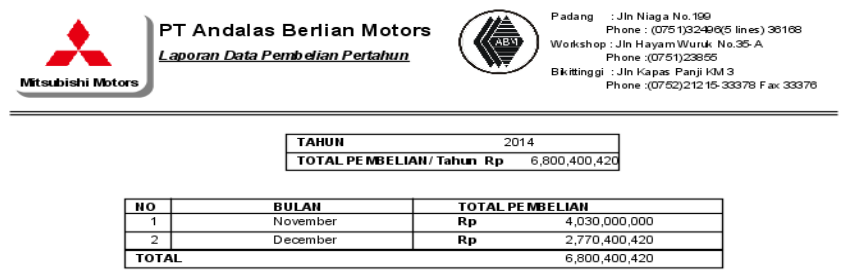

Sumbar, 20 November 2014
PT Andalas Bertian Motors

Manager 
4. Faktur Penjualan

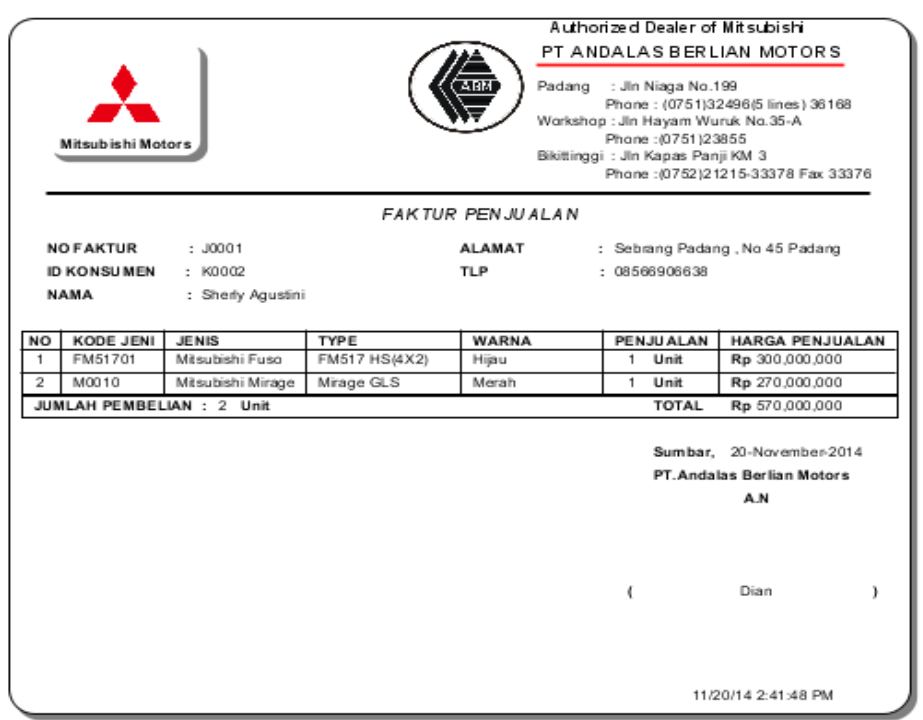

5. Daftar mobil

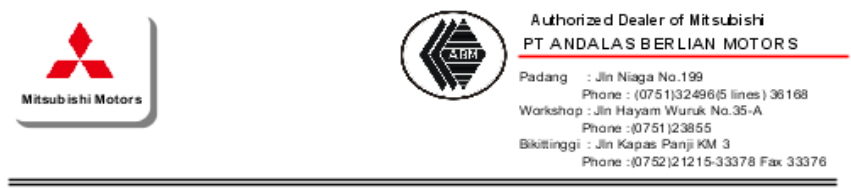

DAFTAR MOBIL

Tang gal : 20-Novenber 2014

\begin{tabular}{|c|c|c|c|c|}
\hline No & \begin{tabular}{|l|} 
KODE JENIS \\
\end{tabular} & TYPE & WARNA & HARGA JUAL \\
\hline 1 & M0001 & Mrage Eroeed & Hipau & Rp $250,000,000.00$ \\
\hline 2 & M00 10 & \begin{tabular}{|l} 
Mrage GLS \\
\end{tabular} & Merah & Rp $\quad 270,000,000.00$ \\
\hline 3 & \begin{tabular}{|l|l|} 
PSD101 \\
\end{tabular} & Pajero Spart Dakar Hi.Power $4 \times 2$ Lim & Hitam & Rp $390,000,000.00$ \\
\hline 4 & M0020 & Mrage GLX & Merah & Rp $280,100,055.00$ \\
\hline 5 & \begin{tabular}{|l|l|} 
PS001 \\
\end{tabular} & Pajer Spart Exoeed $4 \times 2$ Limined $(A)$ & Hisam & Rp $\quad 425,000,100,00$ \\
\hline 6 & \begin{tabular}{|l|} 
PSGO01 \\
\end{tabular} & Pajero Spart GLX $4 X$ (M/T) & Pusth & Rp $425,000,000.00$ \\
\hline 7 & PSD001 & Pajero Spart Dakar Hi.Power 4x4 Lim & Hitam & Rp $475,100,050.00$ \\
\hline 8 & PSGS01 & Pajero Spart GLS 4X2 Limised (M/T) & Hitam & Rp $\quad 450,000,000.00$ \\
\hline 9 & OSGL01 & \begin{tabular}{|l|l|} 
Oulander Spont GLX \\
\end{tabular} & Hitam & Rp $375,100,000.00$ \\
\hline 10 & \begin{tabular}{|l|} 
OSLo01 \\
\end{tabular} & \begin{tabular}{|l|l|} 
Outander Spant Limted \\
\end{tabular} & Hitam & Rp $\quad 465,000,100.00$ \\
\hline 11 & 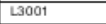 & Coll L300 Piok Up Standard & Hitam & Rp $200,000,000.00$ \\
\hline 12 & OSGS003 & \begin{tabular}{|l|l|} 
Outander Spont GLS \\
\end{tabular} & Silver & Rp $445,100,060.00$ \\
\hline 13 & OSPX001 & Outander Span PX & Silver & Rp $390,100,050.00$ \\
\hline 14 & FM51701 & FM517 HS $\{4 \times 2\}$ & Hị̂ & Rp $300,000,000.00$ \\
\hline
\end{tabular}

6. Daftar Penjualan Perhari

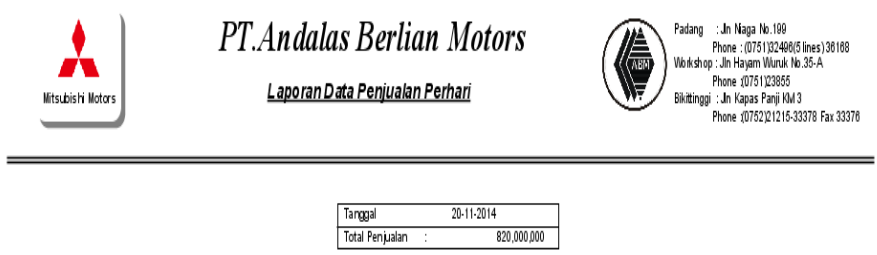

\begin{tabular}{|c|c|c|c|c|c|c|}
\hline 10 NO FAKTUR & MW MA KONSUMEN & JENIS & TYPE & WARNA & PENUUALAN & HARGA JUAL \\
\hline 150001 & Sherely quustii & 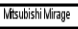 & Whinge QLLS & Werch & 1 loit & $20,000,000$ \\
\hline $\begin{array}{ll}250001 \\
\end{array}$ & \begin{tabular}{|l|l} 
Sherly fousthii \\
\end{tabular} & Mifsubistifi Fuss & 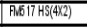 & Hiau & 1 loit & $30,000,000$ \\
\hline $\begin{array}{ll}3 & 50001 \\
\end{array}$ & 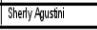 & 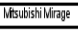 & \begin{tabular}{|l|l|} 
Minge Expeed \\
\end{tabular} & Hiau & 1 Whit & $250,000,000$ \\
\hline
\end{tabular}

Sumbar, 21 Nhverwber 2014

PTAndilas Eerlian hlotors

Wannger 
Veza, Ropianto

7. Daftar Penjualan Perbulan
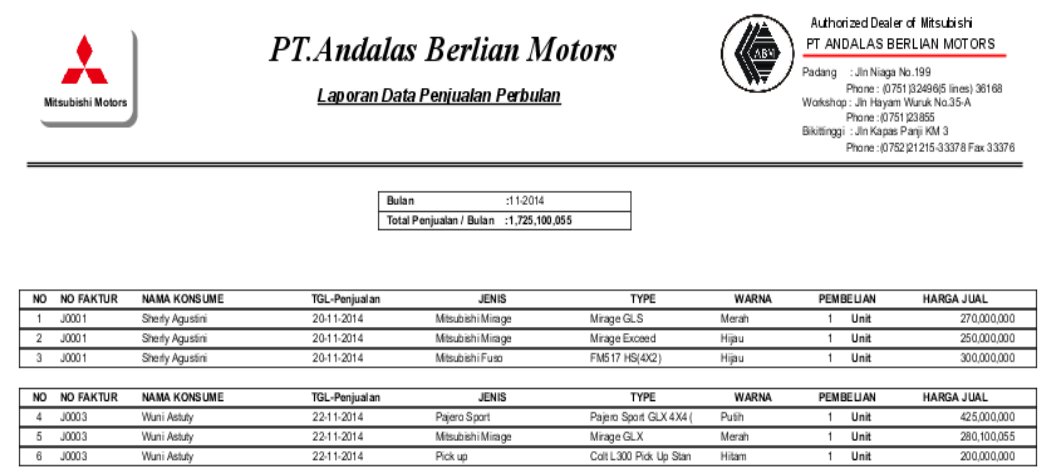

Sumbar, 21 Noverniber 2014
PT Andalas Borfian Mlotors

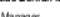

8. Daftar Penjualan Pertahun

PT And alas Berlian Motors
Laporan Data Peniualan Pertahum

\begin{tabular}{|lc|}
\hline TAHUN & 2014 \\
\hline TOTAL PEN JUALAN/Tahun R & $2,900,200,205.0$ \\
\hline
\end{tabular}

\begin{tabular}{|c|c|cr|}
\hline NO & BULAN & \multicolumn{2}{c|}{ TOTAL PEN JUALAN } \\
\hline 1 & November & RP & $1,725,100,055.00$ \\
2 & December & RP & $1,205,100,150.00$ \\
\hline \multicolumn{2}{|l|}{ TOTAL } & RP & $2,900,200,205.00$ \\
\hline
\end{tabular}

Sumbar, 21 November 2014 PT Andal as Berlian Mbtors

Manager

\section{Input}

Berikut Input dari system yang telah dirancang :

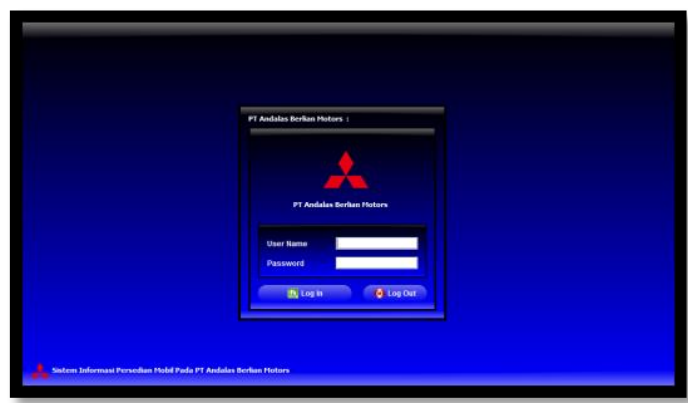

Login

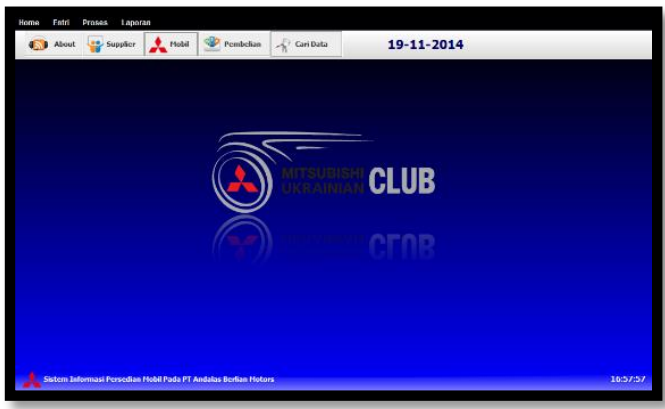

Menu Utama Bagian Gudang 


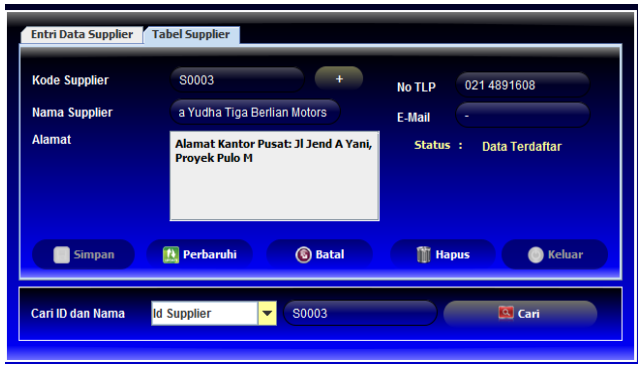

Entri Data Supplier

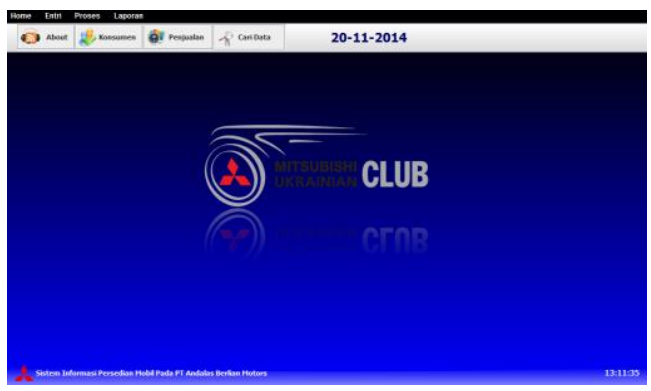

Menu Utama Kasir

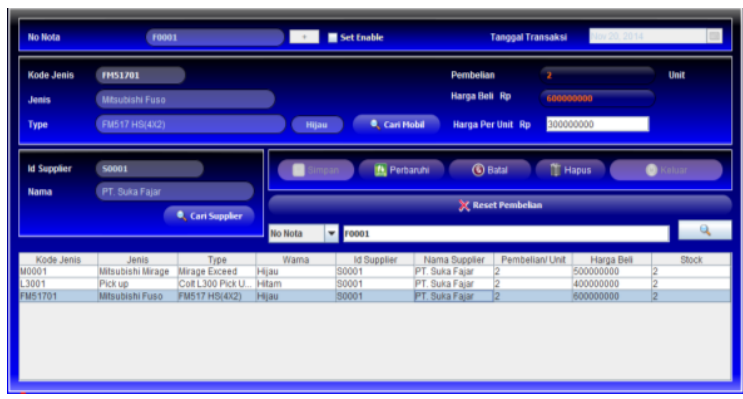

Proses Pembelian

Tabel Suplier

\begin{tabular}{|l|l|l|c|l|}
\hline No & \multicolumn{1}{|c|}{ Nama Field } & Type & Width & \multicolumn{1}{|c|}{ Keterangan } \\
\hline 1 & Id sup & Varchar & 20 & Id Supplier \\
\hline 2 & Nm_sup & Varchar & 35 & Nama Supplier \\
\hline 3 & alamat & Varchar & 50 & Alamat \\
\hline 4 & tlp & Varchar & 15 & Tlp \\
\hline 5 & email & Varchar & 30 & Alamat Email \\
\hline
\end{tabular}

Tabel mobil

\begin{tabular}{|l|l|l|c|l|}
\hline No & Nama Field & Type & Width & \multicolumn{1}{|c|}{ Keterangan } \\
\hline 1 & $\underline{\text { Kd jenis }}$ & Varchar & 20 & Kode Jenis \\
\hline 2 & jenis & Varchar & 35 & Jenis \\
\hline 3 & tp & Varchar & 35 & Type \\
\hline 4 & warna & Varchar & 20 & Warna \\
\hline 5 & st & Double & - & Stock \\
\hline 6 & hgi & Double & - & Harga Jual \\
\hline
\end{tabular}

Tabel Konsumen

\begin{tabular}{|l|l|l|c|l|}
\hline No & \multicolumn{1}{|c|}{ Nama Field } & Type & Width & \multicolumn{1}{|c|}{ Keterangan } \\
\hline 1 & Id kon & Varchar & 20 & Id Konsumen \\
\hline 2 & Nm_kon & Varchar & 35 & Nama Konsumen \\
\hline 3 & alamat & Varchar & 50 & Alamat \\
\hline 4 & tlp & Varchar & 15 & Tlp \\
\hline
\end{tabular}

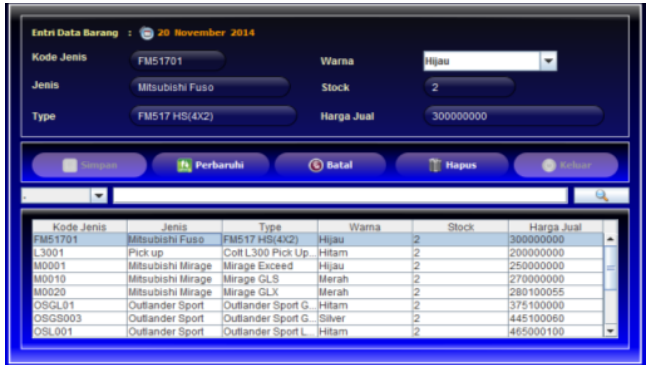

Entri Data Mobil

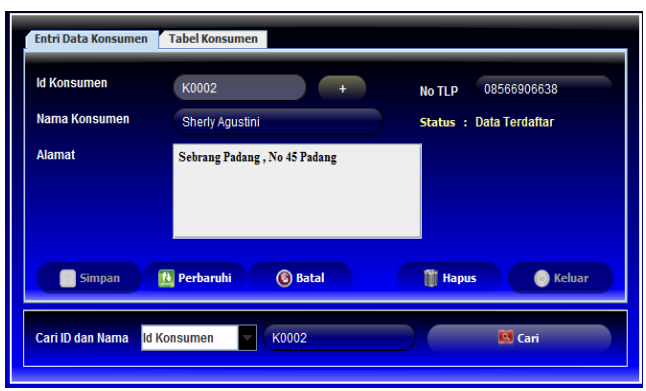

Entri Data Konsumen

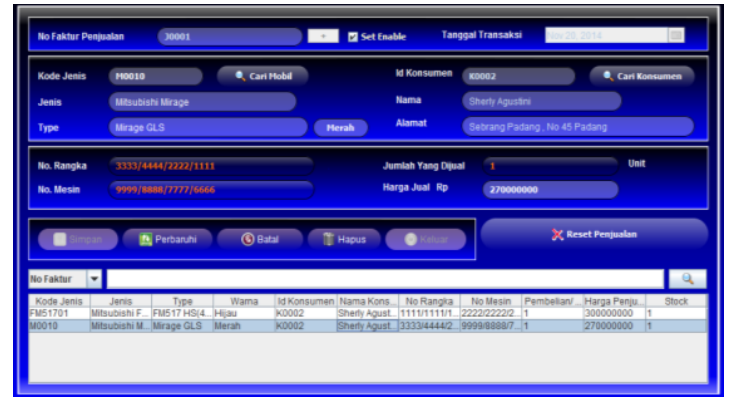

Proses Penjualan

Tabel Pembelian

\begin{tabular}{|l|l|c|c|l|}
\hline No & Nama Field & Type & Width & \multicolumn{1}{|c|}{ Keterangan } \\
\hline 1 & nota & Varchar & 20 & No nota \\
\hline 2 & Tgl_p & Date & - & Tanggal Pembelian \\
\hline 3 & Kd_jenis & Varchar & 20 & Kode Jenis \\
\hline 4 & Id_sup & Varchar & 20 & Id Supplier \\
\hline 5 & bli & Double & - & Jumlah Pembelian \\
\hline 6 & Ag_beli & Double & - & Harga beli \\
\hline
\end{tabular}

\section{Tabel Penjualan}

\begin{tabular}{|l|l|c|c|l|}
\hline No & Nama Field & Type & Width & \multicolumn{1}{|c|}{ Keterangan } \\
\hline 1 & Nofak $i$ & Varchar & 20 & No Faktur Penjualan \\
\hline 2 & Tgl_j & Date & & Tanggal Penjualan \\
\hline 3 & kd_jenis & Varchar & 20 & Kode Jenis \\
\hline 4 & Id_kon & Varchar & 20 & Id Konsumen \\
\hline 5 & No_rangka & Varchar & 20 & Nomor Rangka \\
\hline 6 & No_mesin & Varchar & 20 & Nomor Mesin \\
\hline 7 & jml & Double & - & Jumlah Jual \\
\hline 8 & Ag_jual & Double & - & Harga Jual \\
\hline
\end{tabular}




\section{KESIMPULAN}

Berdasarkan pembahasan yang telah dilakukan pada bab-bab sebelumnya dari skripsi ini, maka penulis dapat mengambil kesimpulan sebagai berikut :

1. Sistem informasi ini memudahkan dalam penyajian laporan yang akurat mengenai penjualan dan pembelian serta pengaruhnya terhadap persediaan

2. Sistem informasi ini memudahkan dalam proses pengecekan atau pencarian data yang dibutuhkan terkait pada transaksi penjualan, dan transaksi pembelian serta pengaruhnya terhadap stock.

3. Aplikasi sistem informasi inventory berfungsi sebagai salah satu tempat penyimpanan data karena sudah memiliki database sehingga antara stock mobil yang masuk dan mobil yang keluar dapat diketahui dengan cepat.

\section{SARAN}

Setelah mengemukakan beberapa kesimpulan dari keseluruhan isi skripsi ini maka penulis dapat mengemukakan saran-saran sebagai berikut :

1. Dengan menerapkan sistem informasi inventory sebaiknya pimpinan perusahaan dapat memberikan pengarahan dan motivasi kepada bagian gudang dan kasir agar dapat menyelesaikan pekerjaan dengan lebih efektif dan efesien.

2. Sistem informasi ini sebaiknya bisa diterapkan secara bertahap dalam pelaksanaannya, dengan kata lain tidak mengabaikan/meninggalkan sistem yang lama.

3. Dalam penerapan program aplikasi ini sebaiknya penggunaan komputer dilengkapi dengan dengan teknologi informasi yang terbaru dengan tujuan agar umur sistem lebih lama dan lebih familiar dengan penggunanya

\section{DAFTAR PUSTAKA}

Abdul Kadir. (2008). Belajar Database Menggunakan MySQL. Yogyakarta: Penerbit C.V. Andi Offset.

Sutarman. (2009). Pengantar Teknologi Informasi. Jakarta: Penerbit PT.Bumi Aksara.

Kusrini. (2007). Strategi Perancangan dan Pengelolaan Basis Data. Yogyakarta: Penerbit C.V. Andi Offset.

Tata Sutabri. (2012). Konsep Sistem Informasi. Yogyakarta: Penerbit C.V. Andi Offset.

Deddy Kusbianto. (2010). Analisa Dan Perancangan Sistem Informasi. Pasuruan: Penerbit STMIK Yadika Bangil.

John Burch,Gary Grudnitski. (2005). Dalam Jogianto Analisa Dan Perancangan Sistem Informasi. Yogyakarta: Penerbit C.V. Andi Offset.

Andri Kristanto. (2008). Perancangan Sistem Informasi dan Aplikasi . Yogyakarta: Penerbit C.V. Andi Offset.

Hanif Al Fatta. (2007). Analisis dan Perancangan Sistem Informasi. Yogyakarta: Penerbit C.V. Andi Offset. 
Fathansyah. (2007). Teks Komputer Basis Data. Bandung: Penerbit Informatika Bandung.

Alexandri. (2009). Manajemen Keuangan Bisnis. Bandung: Penerbit C.V. Alfabeta Bandung.

Ishak. (2010). Manajemen Operasi. Jogyakarta: Penerbit C.V. Graha Ilmu.

Syopiansyah Jaya Putra. (2010). Sistem Informasi Manajemen. Bandung: Penerbit Informatika Bandung.

Fathansyah. (2012). Teks Komputer Basis Data. Bandung: Penerbit Informatika Bandung.

Wahana Komputer. (2006). Pengolahan Database dengan MySQL. Yogyakarta: Penerbit C.V. Andi Offset.

Ir. Yuniar Supardi (2007) Pemrograman Database dengan Java dan MySQL. Jakarta: Elex Media Komputindo.

Benny Hermawan (2007). Menguasai Java 2 dan Object Oriented Programming. Yogyakarta: Penerbit C.V. Andi Offset.

Julius Hermawan (2006). Analisa Desain \& Pemrograman Berorientasi Obyek. Yogyakarta: Penerbit C.V. Andi Offset.

Bambang Hariyanto (2004). Sistem Manajemen Basis Data. Bandung: Penerbit Informatika Bandung.

Tata Sutabri. (2012). Analisis Sistem Informasi. Yogyakarta: Penerbit C.V. Andi Offset.

Yudi Priyadi. (2012). Kolaborasi SQL \& ERD Dalam Implementasi Database. Yogyakarta: Penerbit C.V. Andi Offset.

Indrajani, S.Kom., MM. (2014).Pengantar Sistem Basis Data. Yogyakarta: Penerbit C.V. Andi Offset. 